\title{
Catalytic Activity of Cobalt-Molybdenum in Gas-Phase Ketonisation of Pentanoic Acid
}

\author{
Hossein Bayahia \\ Chemistry Department, Faculty of Science, Albaha University, Albaha, Saudi Arabia
}

Email address:

hbayahia@bu.edu.sa

To cite this article:

Hossein Bayahia. Catalytic Activity of Cobalt-Molybdenum in Gas-Phase Ketonisation of Pentanoic Acid. Science Journal of Chemistry. Vol. 6, No. 1, 2018, pp. 11-16. doi: 10.11648/j.sjc.20180601.12

Received: March 26, 2018; Accepted: April 16, 2018; Published: May 8, 2018

\begin{abstract}
Ketonisation of pentanoic acid over bulk cobalt-molybdenum and its supported catalysts in the gas-phase was investigated using a fixed bed reactor under atmospheric pressure at $320-420^{\circ} \mathrm{C}$. Compared to other supported catalysts, $20 \%$ $\mathrm{Co}-\mathrm{Mo} / \mathrm{Al} 2 \mathrm{O} 3$ demonstrated the best catalytic performance and stability giving to give $95 \% 5$-nonanoe selectivity at $91 \%$ pentanoic acid conversion at $308^{\circ} \mathrm{C}$ and ambient pressure for $5 \mathrm{~h}$ time on stream (TOS).However, its stability was e for $15 \mathrm{~h}$ TOS with small catalytic deactivation. In this study, catalytic characterization was determined using TGA and BET surface area analyses while acidity was measured using FTIR spectroscopy.
\end{abstract}

Keywords: Ketonisation, Pentanoic Acid, Co-Mo Catalysts, Supported Catalysts, 5-Nonanone

\section{Introduction}

Ketonisation reaction is a major component in biorenewable fuels processes and its application in several catalytic reactions is rapidly gaining interest [1-5]. Biomass pyrolysis (decomposition in oxygen-deficient conditions) produces bio-oil from small chain carboxylic acids and is an example of the application of ketonisation. For this purpose, several carboxylic acids have been used. Since ketonisation reaction requires high temperature to produce significant conversions various catalysts have been developed so that the reaction can occur at lower temperatures. Until now, catalytic reaction mechanisms and suitable catalyst properties have not exactly been identified. However, Lewis acid site might be of importance in this reaction. It has been reported that to form intermediate species such as carboxylate in the ketonisation reaction mechanisms, Lewis acid sites on the surface of catalysts are required $[5,6]$.

Ketonisation of carboxylic acids catalyzed by heteropoly acids [7], zeolites [8] and various metal and mixed metal oxides in the gas phase at temperatures of $200-500^{\circ} \mathrm{C}$ has been investigated [9-17]. Albeit several significant researches since the first ketonisation of acetic acid using calcium acetate to produce acetone over the last three decades, ketonisation mechanisms and the nature of catalytic active sites remain unclear [8].
Glinski et al. [18] analysed $\mathrm{MnO}_{2}, \mathrm{CeO}_{2}$ and $\mathrm{ZrO}_{2}$ supported on $\mathrm{Al}_{2} \mathrm{O}_{3}, \mathrm{SiO}_{2}$ and $\mathrm{TiO}_{2}$ catalysts in the gas phase ketonisation of heptanoic acid at $300-450^{\circ} \mathrm{C}$. Previous reports have shown that at low temperatures, $\mathrm{MnO}_{2}$ showed the best catalysts performance compared to $\mathrm{CeO}_{2}$ and $\mathrm{ZrO}_{2}$. Although supported metal and metal oxide catalysts were active in the ketonisation reaction,, $\mathrm{MnO}_{2} / \mathrm{Al}_{2} \mathrm{O}_{3}$ was the most active at $400{ }^{\circ} \mathrm{C}$ to give $95 \%$ of 7 -tridecanone yield. Meanwhile, $\mathrm{CeO}_{2} / \mathrm{Al}_{2} \mathrm{O}_{3}$ and $\mathrm{ZrO}_{2} / \mathrm{Al}_{2} \mathrm{O}_{3}$ gave 82 and $24 \%$ of $7-$ tridecance yields, respectively. In another study, the formation of of 3-pentanone from ketonisation of propionic acid over $\mathrm{CeO}_{2}$ and its composite oxides in the gas phase were investigated at $300-425^{\circ} \mathrm{C}$ for $5 \mathrm{~h}$ TOS. The results of that analysis showed that with increasing temperature, acid conversion also increased, but with a corresponding decrease in ketone selectivity [19]. As the active catalyst, $\mathrm{CeO}_{2}$, with specific surface area of $40.1 \mathrm{~m}^{2} / \mathrm{g}$ gave $93.8 \%$ of 3 pentanone selectivity at $51.0 \%$ acid conversion. However, the mixed oxide catalyst, $\mathrm{CeO}_{2}-\mathrm{Mn}_{2} \mathrm{O}_{3}$ with $38.4 \mathrm{~m}^{2} / \mathrm{g}$ specific surface area, exhibited better activity in the ketonisation reaction. It yielded $97.4 \%$ of 3-pentanone selectivity at $73.9 \%$ acid conversion [14].

At $230^{\circ} \mathrm{C}$, fresh $\mathrm{CeO}_{2}$ catalyst calcined at low temperature was tested in the ketonisation of acetic acid, with a constant mass of catalyst. Previous reports have shown that this temperature was lower compared to the typical temperature 
range used in ketonisation of carboxylic acids over varying catalysts structures and properties. The results showed that greater acetone yields were obtained with $\mathrm{CeO}_{2}$ catalyst that calcined at a low temperature [5].

The formation of acetone by steam reforming acetic acid with 1-bed steam reforming catalyst in a 2-bed catalytic system was investigated. Hydrogen was produced in the single bed while ketonisation of acetic acid occurred in the 2bed catalytic system. Co-based system reforming catalyst under steam atmosphere was also tested in the steam reforming reaction. $\mathrm{MgAl}_{2} \mathrm{O}_{4}, \mathrm{ZnO}, \mathrm{CeO}_{2}$ and activated carbon (without addition) were used as catalyst in the reforming reaction. Co-supported catalyst showed stable catalytic performance with even less coke deposition. Catalytic stability improved with the use of 2-bed catalytic steam reforming of acetic acid to form acetone and coke deposition decreased in comparison to 1-bed steam reforming catalysts [20].

The ketonisation of propionic, acetic and carboxylic acids and using different catalysts have been studied. In a previous study, $\mathrm{Zn}-\mathrm{Cr}$ catalysts as bulk and supported was used in the ketonisation of acetic, propionic and pentanoic acids and they were reported to be active in the reactions [21]. For the ketonisation of pentanoic acid, series of $\mathrm{Zn} / \mathrm{Cr}$ atomic ratio 1:30 to $30: 1, \mathrm{ZnO}$ and $\mathrm{Cr}_{2} \mathrm{O}_{3}$ were tested. Although, all the catalyst showed good catalytic performance, $\mathrm{Zn} / \mathrm{Cr}$ in the ratio $10: 1$ showed the most activity at ambient pressure and $380^{\circ} \mathrm{C}$ as compared with $\mathrm{ZnO}$ and $\mathrm{Cr}_{2} \mathrm{O}_{3}$. At $86 \%$ acid conversion rate, $\mathrm{Zn} / \mathrm{Cr}$ in the ratio $10: 1$ yielded $82 \% 5$ nonanone selectivity . Furthermore, $\mathrm{Zn}-\mathrm{Cr}(1: 10)$ was studied at different temperatures ranging from $300-400^{\circ} \mathrm{C}$ and the results indicated increased catalytic activity at increased temperature of over $380^{\circ} \mathrm{C}$. This could have been due to some coke deposition on the catalyst's surface which might have blocked some of its active sites [19-22].

At conditions of $200-400^{\circ} \mathrm{C}$ and under $\mathrm{N}_{2}$ and $\mathrm{H}_{2}$ atmospheres, the gas-phase ketonisation of propionic acid over Co-Mo bulk and supported catalysts was studied. Supported on alumina, Co-Mo catalyst indicated the most catalytic activity under atmospheric $\mathrm{N}_{2}$ to form 3-pentanone. At $65 \%$ propionic acid conversion ( $44 \%$ ketone yields), the catalyst gave $67 \% 3$-pentanone selectivity compared to $16 \%$ 3 -pentanone at $100 \%$ propionic acid conversion (16\% ketone yields) at similar temperature but under atmospheric $\mathrm{H}_{2}$. Furthermore, catalyst stability was tested for $15 \mathrm{~h}$ TOS under nitrogen atmosphere indicating stable performance but with reduced catalytic activity after $10 \mathrm{~h}$ TOS probably due to coke deposited on its surface [22].

Over Co-Mo bulk and supported catalysts on oxides of alumina $\left(\mathrm{Al}_{2} \mathrm{O}_{3}\right)$, titanium $\left(\mathrm{TiO}_{2}\right)$ and silicon $\left(\mathrm{SiO}_{2}\right)$, , the ketonisation of acetic acid in the gas phase was analyzed under conditions of 1 bar pressure and $200-400^{\circ} \mathrm{C}$ using $0.2 \mathrm{~g}$ catalyst, , 2 vol\% acid and $\mathrm{N}_{2}$ flow rate of $20 \mathrm{mLmin}^{-1}$. Both forms of the catalyst (bulk and supported) showed significant activity in the reaction. For the formation of acetone from acetic acid ketonization, Co-Mo bulk catalyst showed durable catalytic activity for $4 \mathrm{~h}$ TOS to give $91 \%$ selectivity at $86 \%$ acid conversion at $380^{\circ} \mathrm{C}$. However, under similar reaction conditions (in the ketonization of acetic acid), 20\% Co$\mathrm{Mo} / \mathrm{Al}_{2} \mathrm{O}_{3}$ was the most active in comparison with bulk and other supported catalysts to give $91 \%$ acetone yields. With regards to catalytic stability, bulk and supported Co$\mathrm{Mo} / \mathrm{Al}_{2} \mathrm{O}_{3}$ indicated more stability compared to its bulk form at $380^{\circ} \mathrm{C}$ for $12 \mathrm{~h}$ TOS with no deactivation noted during the reaction [23].

The current research analyses the ketonisation of pentanoic acid in the gas phase with bulk Co-Mo and $20 \%$ Co-Mo impregnated on oxides of alumina, titanium and silicon to form 5 -nonanone at $320-420^{\circ} \mathrm{C}, 20 \mathrm{mLmin}^{-1}, 2 \mathrm{vol} \%$ of acid and $0.2 \mathrm{~g}$ catalyst. Different techniques were used to characterize the catalysts. They included BET surface area and porosity while TGA and FTIR-pyridine adsorption were used to measure Lewis and Brensted acid sites on bulk CoMo catalyst surface.

\section{Methodology}

\subsection{Chemicals and Materials}

The chemicals used for this study were purchased from Sigma Aldrich without further purification. They include acetic acid ( $\geq 99.5 \%$ purity), Titanoxid P25, Aerosil ${ }^{\circledR} 300$, and Aluminiumoxid C (Degussa). Catalysts were prepared and washed with distilled water.

\subsection{Preparation of Catalysts}

Cobalt (II) acetate tetrahydrate $\left(\mathrm{Co}\left(\mathrm{CH}_{3} \mathrm{CO}_{2}\right)_{2} \cdot 4 \mathrm{H}_{2} \mathrm{O}\right)$ and molybdenum phosphoric acid $\left(\mathrm{H}_{3} \mathrm{PMo}_{12} \mathrm{O}_{40} \cdot 13 \mathrm{H}_{2} \mathrm{O}\right)$ were dissolved separately in distilled water and then mixed together in a beaker. The mixture was evaporated by a rotary evaporator at $65^{\circ} \mathrm{C}$, and then dried overnight at $110^{\circ} \mathrm{C}$. The preparation of $20 \%$ Co-Mo supported catalysts was done via impregnation on $\mathrm{TiO} 2, \mathrm{Al}_{2} \mathrm{O}_{3}$, and $\mathrm{SiO}_{2}$. Similarly, the bulk catalysts were also prepared by dissolution in distilled water and then added to $\mathrm{Al}_{2} \mathrm{O}_{3}, \mathrm{SiO}_{2}$ and $\mathrm{TiO} 2$. After stirring for 3 $\mathrm{h}$, the reaction mixture was, evaporated, and oven-dried overnight at $110^{\circ} \mathrm{C}$. Lastly, calcination of the catalysts occurred at $400^{\circ} \mathrm{C}$ for $2 \mathrm{~h}$ under $\mathrm{N}_{2}$ atmosphere $[22,23]$.

\subsection{Catalyst Characterisation}

Porosity and surface area of the catalysts were evaluated using the BET method on Micromeritics ASAP 2010 instrument. Measurements for catalytic acidity was obtained with the diffuse reflectance infrared Fourier transform spectra (DRIFTS). The Perkin Elmer TGA 7 analyser under nitrogen atmosphere, was used for thermogravimetric analysis (TGA) to measure the amount of water in the catalysts.

\subsection{Catalyst Testing}

A quartz glass fixed-bed reactor placed in a vertical tube furnace that is fed from the upper part was used for this reaction. At the middle of the catalyst bed, a thermocouple set up on a Eurotherm controller was placed to control the 
reaction temperature. The powdered catalyst $(0.2 \mathrm{~g})$ was loaded in the reactor while pretreatment occurred at the reaction temperature under $20 \mathrm{ml} / \mathrm{min} \mathrm{N}_{2}$ or $\mathrm{H}_{2}$ flow for $1 \mathrm{~h}$. The reaction was carried out at $320-400^{\circ} \mathrm{C}$ under ambient pressure $\mathrm{N}_{2}$ gas flow rate of $20 \mathrm{ml} / \mathrm{min}, 4.0 \mathrm{~g} \mathrm{~h} \mathrm{~mol}^{-1}$ space time and 2 vol \% pentanoic acid concentrations. The Varian $3800 \mathrm{GC}$ was used on Zebron ZB-WAX capillary column of dimensions $30 \mathrm{~m} \times 0.32 \mathrm{~mm} \times 0.5 \mu \mathrm{m}$ at regular intervals to analyse downstream gas flow and)). The equations (1 and 2) below were used to determine acid conversion and selectivity of each product:

$$
\begin{gathered}
\operatorname{conversion}(\%)=\frac{[\text { acid }] \mathrm{o}-[\mathrm{acid}]}{[\mathrm{acid}] \mathrm{o}} \times 100 \\
\text { selectivity of product }(\%)=\frac{\text { yield of product }}{\text { conversion of acid }} \times 100
\end{gathered}
$$

\section{Results and Analysis}

\subsection{Catalyst Characterisation}

Previous investigations have reported on pore volume and diameter, nature of Brønsted and Lewis acid sites and surface area texture [22]. The results of the current study indicated that $20 \% \mathrm{Co}-\mathrm{Mo} / \mathrm{Al}_{2} \mathrm{O}_{3}$ characterized by $97 \mathrm{~m}^{2} / \mathrm{g}$ surface area, pore volume and average pore diameter of 0.12 $\mathrm{cm}^{3} / \mathrm{g}$ and $49 \mathrm{~A}$, respectively, exhibited the best catalytic performance in pentanoic acid ketonisation. These results are similar to those reported in previous studies [22, 23]. Figure 1 shows that there are three bands; the first band at $25-180^{\circ} \mathrm{C}$ indicates the loss of physisorbed water while the second band at $180-490^{\circ} \mathrm{C}$ indicates the structure of water contents. The third band, at $490-700^{\circ} \mathrm{C}$, indicates the decomposition of catalysts with the Keggin structure [22-26]. Similar to a previous study by Bayahia, thermogravimetric analysis (TGA) and FTIR using pyridine adsorption were performed to characterize Bulk Co-Mo catalyst [22, 23].

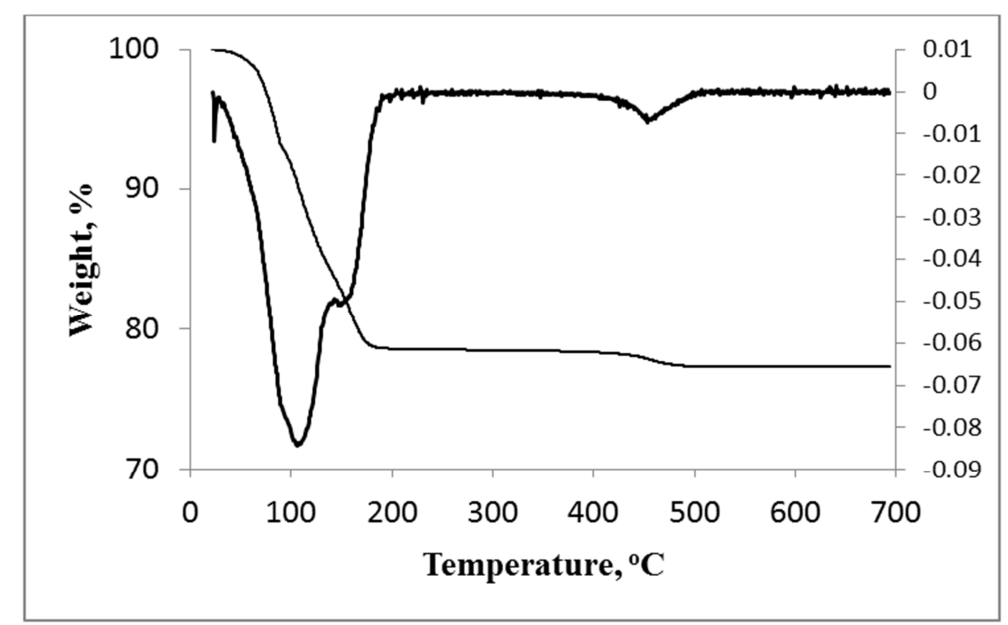

Figure 1. TGA for $20 \% \mathrm{Co}-\mathrm{Mo} / \mathrm{Al}_{2} \mathrm{O}_{3}$.

Figure 2 shows that $20 \% \mathrm{Co}-\mathrm{Mo} / \mathrm{Al}_{2} \mathrm{O}_{3}$ catalyst had $\mathrm{H} 3$ hysteresis loop of an adsorption isotherm and monomodal pore size distribution at the peak with $35.79 \AA$ A pore diameter as shown in Figure 3.

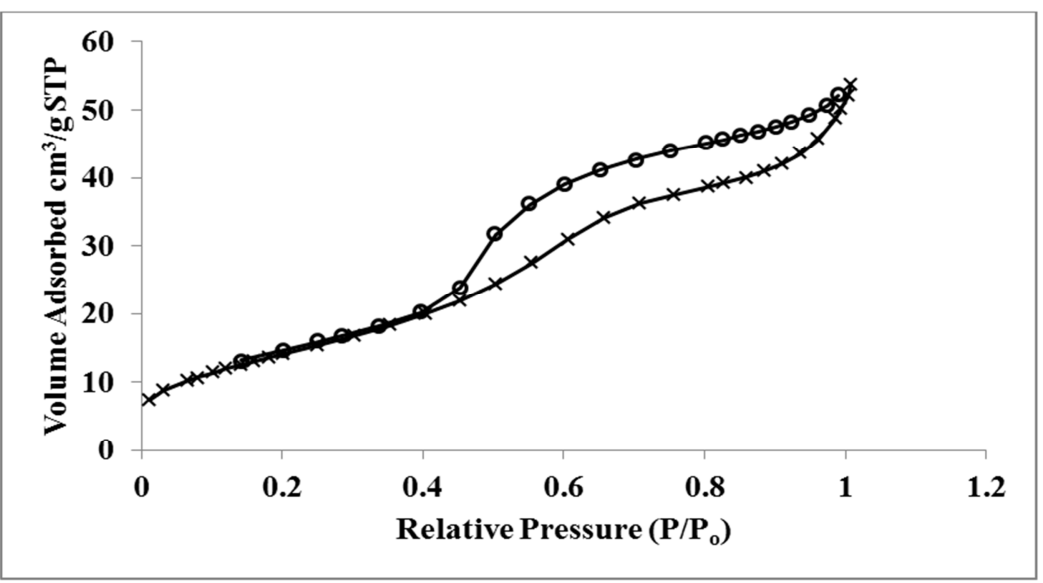

Figure 2. $\mathrm{N}_{2}$ adsorption-desorption on $20 \% \mathrm{Co}-\mathrm{Mo} / \mathrm{Al}_{2} \mathrm{O}_{3}$ at $77 \mathrm{~K}$. The catalyst was pre-treated at $250^{\circ} \mathrm{C}$ in vacuum. 


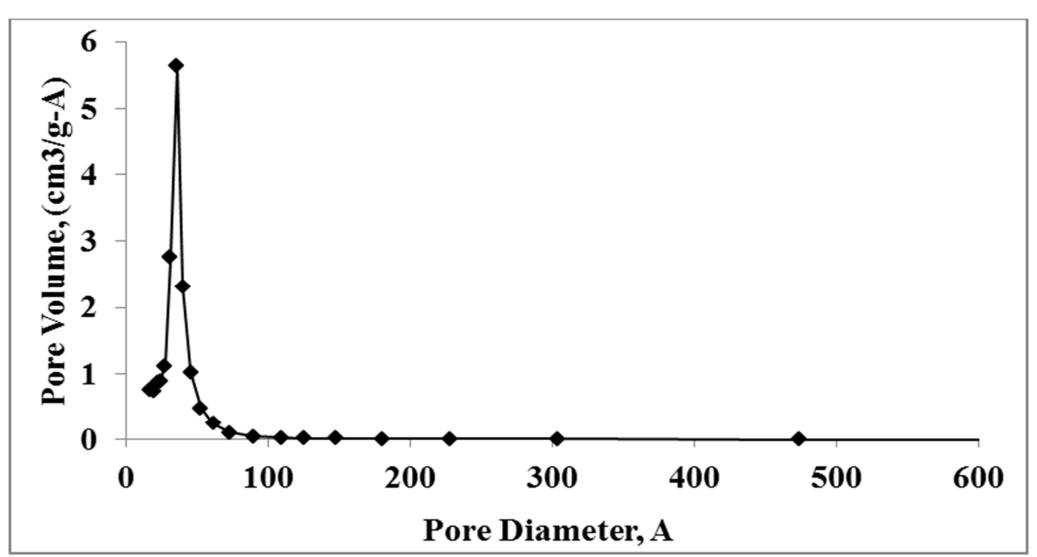

Figure 3. Pore size distribution curve for $20 \% \mathrm{Co}-\mathrm{Mo} / \mathrm{Al}_{2} \mathrm{O}_{3} \mathrm{BJH}$ method. The catalyst was pre-treated at $250^{\circ} \mathrm{C}$ in vacuum.

\subsection{Performance of Catalysts}

\subsubsection{Bulk Co-Mo Catalyst}

Table 1 shows the ketonisation of pentanoic acid in the gas phase over bulk Co-Mo catalyst at $320-420^{\circ} \mathrm{C}$. These results indicate significant catalytic activity of the bulk catalyst in the ketonisation reaction and its positive correlation with temperature. Hence, with increased temperature, catalytic activity increased. Thus, the best catalytic activity was shown at $380^{\circ} \mathrm{C}$ to give $91 \% 5$-nonanone selectivity at $80 \%$ acid conversion. The amount of hydrocarbons formed as byproducts increased with increasing temperature. However, there were some unknown products (probably, isopropanol or propanol and propanal) that also slightly increased in amount with increasing temperature. The amount of carbon monoxide and carbon dioxide were not monitored.

Table 1. Ketonisation of pentanoic acid over bulk Co-Mo catalyst ${ }^{a}$.

\begin{tabular}{|c|c|c|c|c|}
\hline \multirow{2}{*}{ Temperature $\left({ }^{\circ} \mathrm{C}\right)$} & \multirow{2}{*}{ Conversion (\%) } & \multicolumn{3}{|c|}{ Selectivity (\%) } \\
\hline & & 5-nonanone & Hydrocarbons & Unknown $^{b}$ \\
\hline 320 & 17 & 96 & 2 & 2 \\
\hline 350 & 29 & 93 & 3 & 4 \\
\hline 380 & 80 & 91 & 5 & 4 \\
\hline 400 & 87 & 79 & 13 & 8 \\
\hline 420 & 93 & 74 & 17 & 9 \\
\hline
\end{tabular}

${ }^{a} 1$ bar pressure, $0.2 \mathrm{~g}$ of catalyst, $20 \mathrm{mLmin}^{-1} \mathrm{~N}_{2}$ flow rate, and $2 \mathrm{vol} \%$ of acid, $5 \mathrm{~h}$ TOS.

${ }^{\mathrm{b}}$ Probably isopropanol, propanol or propanal; $\mathrm{CO}$ and $\mathrm{CO}_{2}$ not included.

\subsubsection{Supported Co-Mo Catalysts}

Catalytic activity improved with supported $20 \%$ Co-Mo on $\gamma-\mathrm{Al}_{2} \mathrm{O}_{3}, \mathrm{SiO}_{2}$ and $\mathrm{TiO}_{2}$. Both $\mathrm{Al}_{2} \mathrm{O}_{3}$ and $\mathrm{TiO}_{2}$ showed better catalytic performance in comparison with $\mathrm{SiO}_{2}$ to form 5nonanone from the pentanoic acid ketonisation in the gasphase (Table 2). It was found that Co-Mo supported catalysts possess significant amount of Brensted and Lewis acid sites which explains their activity in the ketonisation reaction [22, 23]. However, $\mathrm{SiO}_{2}$ was shown to be inactive at temperatures $<400^{\circ} \mathrm{C}$ (Table 2). However, it was shown to be active at higher temperatures as previously reported [23]. Interestingly, at $380^{\circ} \mathrm{C}, 20 \% \mathrm{Co}-\mathrm{Mo} / \mathrm{Al}_{2} \mathrm{O}_{3}$ exhibited superior catalytic activity to give $95 \%$ ketone selectivity at $91 \%$ acid conversion.

Furthermore, $20 \% \mathrm{Co}-\mathrm{Mo} / \mathrm{Al}_{2} \mathrm{O}_{3}$ was used in the long term ketonisation of pentanoic reaction to investigate its catalytic activity. Stable catalytic performance was exhibited by the catalyst for $15 \mathrm{~h}$ TOS with a slight reduction in catalyst conversion from $91 \%$ at the first hour of reaction to $83 \%$ ketone selectivity (Figure 4). Similar results were obtained in acetic and propionic acids ketonization in the gas-phase using the same catalyst $[22,23]$. On the other hand, catalytic deactivation may be due to several reasons such as poisoning, fouling and thermal degradation etc [23, 27]. Therefore, the deactivation of $20 \% \mathrm{Co}-\mathrm{Mo} / \mathrm{Al}_{2} \mathrm{O}_{3}$ might have occurred due coke deposition on the catalyst's surface thus, effectively blocking its active sites [23]. $\mathrm{C}, \mathrm{H}$ analysis was used to determine that the amount of coke found on the catalyst measured $2.7 \mathrm{wt} \%$.

Table 2. Ketonisation of pentanoic acid over Co-Mo/supported catalysts.

\begin{tabular}{llllll}
\hline \multirow{2}{*}{ Catalyst } & Temperature $\left({ }^{\circ} \mathbf{C}\right)$ & \multirow{2}{*}{ Conversion (\%) } & & Selectivity (\%) & \\
\cline { 5 - 6 } & & 0 & 5 -nonanone & Hydrocarbons & Unknown $^{\mathbf{b}}$ \\
\hline $\mathrm{SiO}_{2}$ & 380 & 33 & 90 & 0 & 0 \\
$\mathrm{Al}_{2} \mathrm{O}_{3}$ & 380 & 70 & 55 & 4 & 6 \\
$\mathrm{TiO}_{2}$ & 380 & & 32 & 13 \\
\hline
\end{tabular}




\begin{tabular}{llllll}
\hline \multirow{2}{*}{ Catalyst } & Temperature $\left({ }^{\circ} \mathbf{C}\right)$ & \multirow{2}{*}{ Conversion (\%) } & & Selectivity (\%) & \\
\cline { 5 - 6 } & & 47 & 5-nonanone & Hydrocarbons & Unknown $^{\mathbf{b}}$ \\
\hline $20 \% \mathrm{Co}-\mathrm{Mo} / \mathrm{SiO}_{2}$ & 380 & 72 & 98 & 2 & 0 \\
$20 \% \mathrm{Co}-\mathrm{Mo} / \mathrm{TiO}_{2}$ & 380 & 51 & 93 & 5 & 2 \\
$20 \% \mathrm{Co}-\mathrm{Mo} / \mathrm{Al}_{2} \mathrm{O}_{3}$ & 320 & 64 & 96 & 2 & 0 \\
$20 \% \mathrm{Co}-\mathrm{Mo} / \mathrm{Al}_{2} \mathrm{O}_{3}$ & 350 & 91 & 95 & 3 & 1 \\
$20 \% \mathrm{Co}-\mathrm{Mo} / \mathrm{Al}_{2} \mathrm{O}_{3}$ & 380 & 96 & 78 & 4 & 1 \\
$20 \% \mathrm{Co}-\mathrm{Mo} / \mathrm{Al}_{2} \mathrm{O}_{3}$ & 410 & 96 & 6 \\
\hline
\end{tabular}

${ }^{a} 1$ bar pressure, $0.2 \mathrm{~g}$ of catalyst, $20 \mathrm{mLmin}^{-1} \mathrm{~N}_{2}$ flow rate, and 2 vol $\%$ of acid, $5 \mathrm{~h}$ TOS.

${ }^{\mathrm{b}}$ might be isopropanol, propanol or propanal; $\mathrm{CO}$ and $\mathrm{CO}_{2}$ not included.

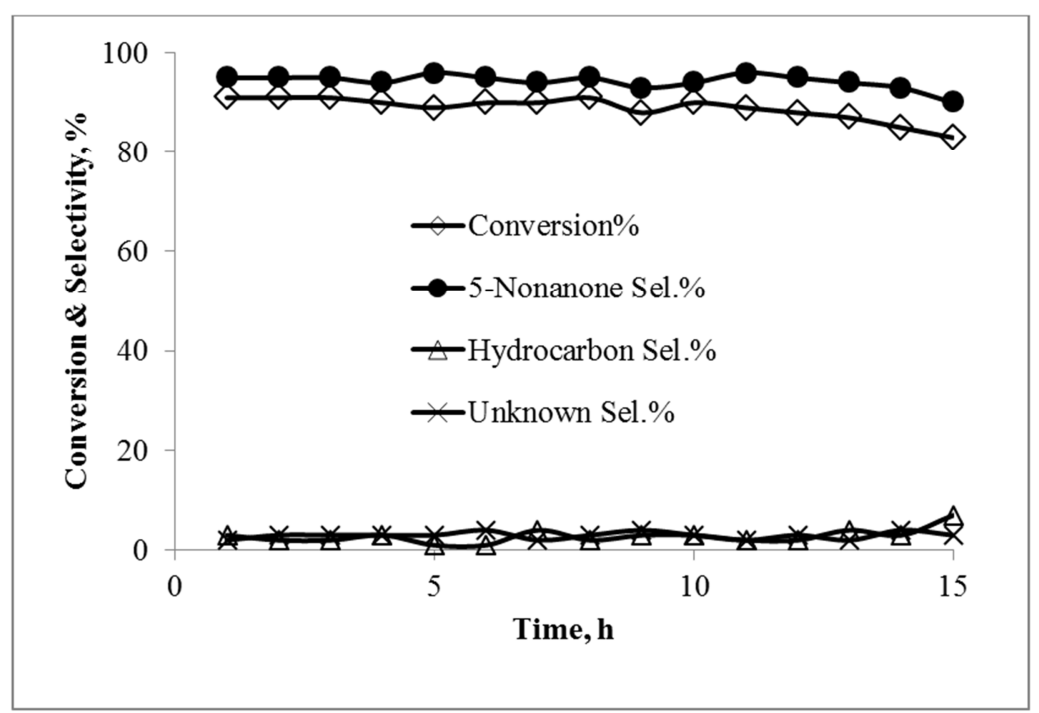

Figure 4. Catalytic stability of ketonisation of pentanoic acid over $0.2 \mathrm{~g}$ of $20 \% \mathrm{Co}-\mathrm{Mo} / \mathrm{Al}_{2} \mathrm{O}_{3}$ for $15 \mathrm{~h} \mathrm{TOS}$ at $380^{\circ} \mathrm{C}, 20 \mathrm{~mL} / \mathrm{min} \mathrm{N}_{2}, 2 \mathrm{vol} \%$ of pentanoic acid, $4.0 \mathrm{~h} \mathrm{~mol}^{-1}$ space time.

\section{Conclusion}

Bulk Co-Mo has been shown to be an active and stable catalyst in pentanoic acid ketonisation in the gas-phase at $320-400^{\circ} \mathrm{C}$ under atmospheric pressure to form 5-nonanone. Supported on $\mathrm{SiO}_{2}, \quad \gamma-\mathrm{Al}_{2} \mathrm{O}_{3}$ and $\mathrm{TiO}_{2}$, the catalytic performance of bulk Co-Mo was improved. Of these catalysts, $20 \%$ Co-Mo supported on $\gamma-\mathrm{Al}_{2} \mathrm{O}_{3}$ showed superlative catalytic performance in to give $95 \%$ selectivity at $91 \%$ pentanoic acid conversion at $380^{\circ} \mathrm{C}$ for $5 \mathrm{~h}$ TOS. Its stability lasted for $15 \mathrm{~h}$ TOS with small deactivation in its catalytic activity. Several techniques were employed to characterize both forms of catalysts. They include BrunauerEmmett-Teller (BET) surface area and porosity analysis while TGA analysis and DRIFTS of adsorbed pyridine were used to measure the acidity of the catalysts.

\section{Conflicts of Interest}

The author declares that competing interests do not exist.

\section{References}

[1] E. L. Kunkes, D. A. Simonetti, R. M. West, J. C. SerranoRuiz, C. A. Gartner, J. A. Dumesic, Science, 322, 2008, 417421
[2] C. A. Gaertner, J. C. Serrano-Ruiz, D. J. Braden, J. A. Dumesic, Journal of Catalysis, 266, 2009, 71-78.

[3] C. A. Gaertner, J. C. Serrano-Ruiz, D. J. Braden, J. A. Dumesic, ChemSusChem., 2, 2009, 1121-1124.

[4] E. Karimi, C. Briens, F. Berruti, S. Moloodi, T. Tzanetakis, M. J. Thomson, M. Schlaf, Energy Fuel, 24, 2010, 6586-6600.

[5] Ryan W. Snell, Brent H. Shonks, Applied Ctalysis A: General, 451, 2013, 86-93.

[6] M. A. Hasan, M. I. Zaki, I. Pasupulety. Applied Catalysis A: General, 243, 2003, 81-92.

[7] M. A. Alotaibi, E. F. Kozhevnikova and. V. Kozhevnikov, Applied Catalysis A: General, 2012, 447-448, 32-40.

[8] H. Bayahia, E. Kozhevnikov and I. Kozhevnikov, Chemical Communication, 2013, 49, 3842-3844.

[9] M. Renz, European Journal of Organic Chemistry, 2005, 979988.

[10] T. N. Pham, T. Sooknoi, S. P. Crossley and D. E. Resasco, ACS Catalysis, 2013, 3, 2456-2473.

[11] A. D. Murkute, J. E. Jackson and D. J. Miller, Journal of Catalysis, 2011, 278, 189-199.

[12] T. Yokoyama and N. Yamagata, Applied Catalysis A: General, 2001, 221, 227-239.

[13] J. A. Martens, M. Wydoodt, P. Espeel and P. A. Jacobs, Editon edn., 1993, vol. 78, pp. 527-534. 
[14] O. Nagashima, S. Sato, R. Takahashi and T. Sodesawa, Journal of Molecular Catalysis A: Chemical, 2005, 227, 231239.

[15] C. A. Gaertner, J. C. Serrano-Ruiz, D. J. Braden and J. A. Dumesic, Industrial and Engineering Chemistry Research, 2010, 49, 6027-6033.

[16] H. Benaissa, P. N. Davey, Y. Z. Khimyak and I. V. Kozhevnikov, Journal of Catalysis, 2008, 253, 244-252.

[17] H. Benaissa, P. N. Davey, E. F. Kozhevnikova and I. V. Kozhevnikov, Applied Catalysis A: General, 2008, 351, 88-92.

[18] M. Gliński, and J. Kijeński, Applied Catalysis A, General, 2000, 190, 87-91.

[19] H. Bayahia, E. F. Kozhevnikova and I. V. Kozhevnikov, Applied Catalysis B: Environmental, 2015, 165, 253-259.

[20] Stephen D. Davidson, Kurt A. Spies, Donghai Mei, Libor Kovarik, Igor Kutnyakov, Xiaohong S. Li, Vanessa Lebarbier Dagle, Karl O. Albrecht, and Robert A. Dagle, ACS Sustainable Chem. Eng., 5 (10), 2017, 9136-9149.
[21] Mohammed Saad Mutlaq Al-Ghamdi and Hossein Bayahia, Mediterranean Journal of Chemistry, 6, 2017, 1-6.

[22] Hossein Bayahia, Asian Journal of Chemistry, 28, 2016, 27442748.

[23] Hossein Bayahia, Journal of Taibah University for Science, DIO: 10.1080/16583655.2018.1451064, 2018, 1-6. https://doi.org/10.1080/16583655.2018.1451064

[24] A. Aoussi, A. W. Apblett, Z. A. Al-Othman and A. Al-Amro, Transition Metal Chemistry, 35, 927, 2010.

[25] C. S. Song, C. S. Hsu, and I. Mochida, Chemistry for Desel, Applied Energy Technology series, 140, 2000.

[26] M. Arend, T. Nonnen, W. F. Hoeldrich, J. Fischer, and J. Groos, Applied Catalyst: A, 447, 32, 2013.

[27] Morris D. Argyle and Calvin H. Bartholomew, Catalysis, 2015, 5(1), 145-269. 